\title{
Transfusion requirements of adolescents with severe haemophilia A
}

\author{
A. ARONSTAM, D. S. McLELlan, AND P. TURK \\ From the Haemophilia Centre, Lord Mayor Treloar Hospital, Alton, Hants, UK
}

SUMMARY The transfusion requirements of 75 adolescents with severe haemophilia A were studied during the five-year period 1973-77. The annual incidence of the 4935 episodes studied increased by a factor of $2 \cdot 2$ while the number of transfusions rose by a factor of 2.5 and the amount of therapeutic material used during the five years of the survey increased by a factor of $2 \cdot 6$. A further 166 bleeds occurred during periods of prophylaxis in 1976 and 1977, which generated a $25 \%$ increase in factor VIII used during those years. The increased usage of factor VIII in the years 1976 and 1977 was thus due mainly to increased numbers of transfusions given per bleed and to the use of prophylaxis but also to a slight increase in the units of factor VIII given in each dose. Twice weekly prophylaxis reduced the bleeding frequency by $30 \%$ and resulted in an increase of about $12 \%$ in usage of factor VIII. Prophylaxis given three times weekly reduced the bleeding frequency by about $60 \%$ at the cost of an increase of $77 \%$ in therapeutic materials.

Iliopsoas, retroperitoneal, and abdominal wall bleeds were the commonest bleeds needing retransfusion within 24 hours, while bleeds into the extremities of the upper and lower limbs needed least retransfusions within 24 hours. Retroperitoneal bleeds needed the most transfusions per episode followed by iliopsoas, buttock, abdominal wall, and hip joint bleeds. The transfusion requirements of bleeds below the diaphragm tended to diminish steadily the more peripheral they became. This relationship did not hold for upper limb bleeds.

The transfusion requirements of haemophiliacs in this country have been escalating steadily (Biggs and Spooner, 1977a, 1977b), thus rapidly outdating successive forecasts of future requirements. A haemophiliac population bulge exists betweer the ages of 10 and 19 years (Biggs and Spooner, 1977a), and close observation of the transfusion requirements of a group of severely affected adolescent haemophiliacs should yield information which may help in the prediction of future requirements. An analysis of the transfusion requirements for bleeds at specific sites may also be helpful in the planning of dose requirements for bleeds at those sites.

The Lord Mayor Treloar College is a school for handicapped children, and at any given time about 55 of its pupils are severe haemophiliacs. During school terms these haemophiliac children are under constant medical supervision, and all bleeding episodes and transfusions are fully documented. We present here a review of the transfusion requirements of haemophiliac boys at this College between 1973 and 1977.

Received for publication 2 March 1979

\section{Patients and methods}

Seventy-five boys without inhibitors and with haemophilia A were studied during the years 197377. The age of the boys under study ranged between 9 and 17 years. All had factor VIII levels of less than $1 \%$.

Prophylactic factor VIII was given to 15 of the boys for limited periods during 1976 and 1977. Prophylaxis was administered twice weekly to five boys during 1976 and three times weekly to 13 boys during 1976 and 1977 . The bleeding frequency before prophylaxis was taken as that over the previous two school terms. The periods on prophylaxis, together with the bleeds and transfusions occurring during that time, have been considered separately. Occasionally bleeds occurred at more than one site simultaneously. This situation was recorded as a single bleeding episode, but if more than one transfusion was needed the multiple transfusions were recorded for each separate site.

Each transfusion was of cryoprecipitate, National Health Service factor VIII concentrate, or commercial factor VIII concentrate and was recorded as a 927 
single transfusion irrespective of dose. The strength of cryoprecipitate, which was supplied by the Wessex Regional Transfusion Centre at Southampton, was monitored by frequent assays of recovery in vivo and assay of the bags in vitro. On this basis each donor unit was assumed to contain 75 international units of factor VIII during the years 1973-75 and 100 international units in 1976 and 1977.

Factor VIII $_{c}$ assays were carried out by a twostage method based on that of Denson (1972).

The levels of factor VIII aimed at in vivo to treat bleeding episodes were dependent on the site and severity of the lesion. As a general rule, for an uncomplicated joint bleed the factor VIII level was raised to $20 \%$ of average normal, while for severe or complicated joint bleeds and muscle bleeds a $30 \%$ rise was aimed at. The amount of factor VIII required to achieve the desired rise was derived from the formula:

Dose (units) $=$

Patient's weight (kilograms) $\times$ desired rise in factor VIII

$$
\mathrm{K}
$$

In the present study $\mathrm{K}$ was taken to be $1 \cdot 5$.

All bleeds and their subsequent progress were assessed by one of the medical staff. Although several boys were able to transfuse themselves, the decision to transfuse was always a medical one.

Our indications for retransfusion within 24 hours were evidence of extension of bleeding at 12 hours or poor progress after 24 hours. Further transfusions were given to cover rehabilitation or for complicated or poorly resolving bleeds.

All boys were weighed at the beginning of each term. The average of all their weights for the year was taken as a mean for that year.

\section{Results}

Altogether 4935 episodes were recorded in the 75 boys during periods when they were not on prophylaxis. The number of bleeding episodes rose by a factor of $2 \cdot 2$ from 639 in 1973 to 1391 in 1977, while the number of transfusions rose by a factor of 2.5 from 782 in 1973 to 1931 in 1977 . Over the same period the amount of therapeutic material used has risen by a factor of 2.6 from 561640 units of factor VIII in 1973 to 1453340 in 1977 (Table 1).

Table 1 Bleeding episodes and transfusions

\begin{tabular}{lllll}
\hline Year & Patients & Bleeds & Transfusions & $\begin{array}{l}\text { Units FVIII } \\
\left(\times 10^{3}\right)\end{array}$ \\
\hline 1973 & 39 & 639 & 782 & 562 \\
1974 & 43 & 708 & 873 & 600 \\
1975 & 49 & 948 & 1359 & 865 \\
1976 & 54 & 1249 & 1781 & 1238 \\
1977 & 51 & 1391 & 1931 & 1453 \\
Total & 75 & 4935 & 6726 & 4718 \\
\hline
\end{tabular}

The average weight of the haemophiliacs during each year of the study is shown in Table 2, which also shows the annual usage of factor VIII per bleed and per kilogram per bleed, as well as the annual usage of factor VIII per transfusion and per kilogram per transfusion. The annual usage of factor VIII per bleed has risen from 879 in 1973 to 1045 in 1977, a factor of $1 \cdot 2$. This increase occurred between 1974 and 1975 and was sustained in the three years 1975-77. The units of factor VIII given per kilogram per bleed have increased by a factor of 1.2 from 19.1 in 1973 to 22.7 in 1977 . There has been no significant change in the units per dose and the units per kilogram per dose over the years of the survey.

The effect of prophylaxis on transfusion requirements and bleeding frequencies is shown in Tables 3 and 4. Twice weekly prophylaxis was able to reduce the bleeding frequency from 13.4 to 9.4 bleeds per 100 days. On this regime 795 units per dose were used and each dose averaged 17.0 units per kilogram; 1657 units were used for each bleed at a dose of 36 units per $\mathrm{kg}$ per bleed. Thrice weekly prophylaxis reduced the bleeding frequency of 13 boys from 16 bleeds per 100 days to 5.9 bleeds per 100 days. On this regime 730 units per dose were used and each dose averaged 15.0 units per kilogram; 4809

Table 2 Dosage of factor VIII

\begin{tabular}{|c|c|c|c|c|c|c|}
\hline \multirow[t]{2}{*}{ Year } & \multirow[t]{2}{*}{ Patients } & \multirow{2}{*}{$\begin{array}{l}\text { Average weight } \\
(\mathrm{kg})\end{array}$} & \multicolumn{4}{|c|}{ Units FVIII } \\
\hline & & & Perbleed & Per kg per bleed & Per transfusion & Per $k g$ per transfusion \\
\hline $\begin{array}{l}1973 \\
1974 \\
1975 \\
1976 \\
1977\end{array}$ & $\begin{array}{l}39 \\
43 \\
49 \\
54 \\
51\end{array}$ & $\begin{array}{l}46 \\
47 \\
44 \\
45 \\
46\end{array}$ & $\begin{array}{r}879 \\
848 \\
912 \\
991 \\
1045\end{array}$ & $\begin{array}{l}19 \cdot 1 \\
18.0 \\
20.7 \\
20.0 \\
22.7\end{array}$ & $\begin{array}{l}718 \\
687 \\
637 \\
695 \\
753\end{array}$ & $\begin{array}{l}15.6 \\
14.6 \\
13.0 \\
15.4 \\
16.4\end{array}$ \\
\hline Mean & & $45 \cdot 6$ & 956 & $21 \cdot 0$ & 701 & $15 \cdot 4$ \\
\hline
\end{tabular}


Table 3 Effect of prophylaxis on bleeding frequency

\begin{tabular}{lrrrrr}
\hline & Patients & Days & Bleeds & Bleeds/100 days & Previous bleeds/IO0 days \\
\hline 1976 & 7 & 1351 & 88 & $6 \cdot 5$ & $15 \cdot 1$ \\
1977 & 13 & 1240 & 78 & $6 \cdot 3$ & $15 \cdot 8$ \\
Twice weekly & 5 & 374 & 35 & $9 \cdot 4$ & $13 \cdot 4$ \\
Thrice weekly & 13 & 2217 & 131 & $5 \cdot 9$ & $16 \cdot 0$ \\
\hline
\end{tabular}

Table 4 Consumption of factor VIII on prophylaxis

\begin{tabular}{|c|c|c|c|c|c|c|}
\hline & \multirow{2}{*}{$\begin{array}{l}\text { No. of } \\
\text { transfusions }\end{array}$} & \multicolumn{5}{|c|}{ Units FVIII } \\
\hline & & $\times 10^{3}$ & Per transfusion & Per kg per transfusion & Per bleed & Per kg per bleed \\
\hline $\begin{array}{l}1976 \\
1977 \\
\text { Twice weekly } \\
\text { Thrice weekly }\end{array}$ & $\begin{array}{r}447 \\
489 \\
73 \\
863\end{array}$ & $\begin{array}{r}339 \\
349 \\
58 \\
630\end{array}$ & $\begin{array}{l}758 \\
714 \\
795 \\
730\end{array}$ & $\begin{array}{l}17 \\
14 \\
17 \\
15\end{array}$ & $\begin{array}{l}3852 \\
4474 \\
1657 \\
4809\end{array}$ & $\begin{array}{r}86 \\
91 \\
36 \\
101\end{array}$ \\
\hline
\end{tabular}

Table 5 Retransfusions for bleeds into the 18 commonest sites

\begin{tabular}{|c|c|c|c|c|}
\hline \multirow[t]{2}{*}{ Site } & \multirow[t]{2}{*}{ No. of bleeds } & \multicolumn{2}{|c|}{ Bleeds retransfused in 24 hours } & \multirow[t]{2}{*}{ Transfusions per bleed } \\
\hline & & No. & Percentage & \\
\hline Iliopsoas & 73 & 45 & 61.6 & $2 \cdot 5$ \\
\hline Retroperitoneal & 17 & 10 & $58 \cdot 8$ & 3.6 \\
\hline Abdominal wall & 26 & 11 & $42 \cdot 3$ & $1 \cdot 6$ \\
\hline Buttock & 59 & 18 & $30 \cdot 5$ & $1 \cdot 7$ \\
\hline Thigh & 224 & 58 & 25.9 & 1.4 \\
\hline Hip & 59 & 13 & $22 \cdot 0$ & 1.6 \\
\hline Calf & 121 & 25 & $20 \cdot 7$ & $1 \cdot 4$ \\
\hline Wrist & 139 & 25 & $17 \cdot 3$ & $1 \cdot 2$ \\
\hline Knee & 1184 & 187 & $15 \cdot 8$ & $1 \cdot 2$ \\
\hline Shoulder & 317 & 45 & $14 \cdot 2$ & $1 \cdot 2$ \\
\hline Ankle & 758 & 105 & 13.9 & $1 \cdot 2$ \\
\hline Forearm & 185 & 21 & 11.4 & $1 \cdot 2$ \\
\hline Elbow & 1279 & 143 & $11 \cdot 2$ & $1 \cdot 2$ \\
\hline Upper arm & 171 & 18 & $10 \cdot 5$ & $1 \cdot 1$ \\
\hline Fingers & 85 & 8 & $9 \cdot 4$ & $1 \cdot 1$ \\
\hline Hand & 86 & 7 & $8 \cdot 1$ & $1 \cdot 1$ \\
\hline Foot & 75 & 5 & $6 \cdot 7$ & $1 \cdot 1$ \\
\hline Toes & 70 & 2 & 2.9 & $1 \cdot 0$ \\
\hline Total & 4928 & 745 & $15 \cdot 1$ & $1 \cdot 2$ \\
\hline
\end{tabular}

units of factor VIII were used for each bleed at a dose level of 101 units per $\mathrm{kg}$ per bleed.

The transfusion requirements for bleeding episodes into the 18 commonest sites are shown in Table 5. More iliopsoas bleeds needed transfusion within 24 hours $(61.6 \%)$ than bleeds into any other site, followed by retroperitoneal $(58.8 \%)$ and abdominal wall bleeds $(42 \cdot 3 \%)$. The least retransfusions were used for bleeds into the hand $(8 \cdot 1 \%)$, foot $(6 \cdot 7 \%)$, and toes $(2 \cdot 9 \%)$. Retroperitoneal bleeds required most transfusions per bleed (3.6) followed by iliopsoas bleeds $(2.5$ transfusions per bleed) and bleeds into the buttocks ( $1 \cdot 7$ transfusions per bleed). Bleeds into the upper arm musculature, hands, fingers, feet, and toes required the least transfusions per bleed.

\section{Discussion}

There was a marked increase in the use of therapeutic materials at this Centre between 1973 and 1977. A large part of this can be accounted for by the increased bleeding frequency of pupils at the College over the years of the study. The reasons for this have been discussed elsewhere (Aronstam et al., 1979). The average amount of factor VIII per dose and the units of factor VIII per kilogram per dose have remained relatively constant over the five years while the number of transfusions has risen by more than the number of bleeds. An increase in the number of transfusions rather than the amount of factor VIII per transfusion therefore accounts for some of the increased usage of factor VIII. This 
is confirmed by the increase in the units per bleed and units per kilogram per bleed, each up by a factor of 1.2 over the period of our survey. The implication is that we have increased the transfusions given per bleed by about one-fifth between 1973 and 1977 .

The use of prophylaxis resulted in an overall increase of about one-quarter in the factor VIII used during 1976 and 1977 . While on prophylaxis the boys consumed about four times more factor VIII per bleed than the average for all boys not on prophylaxis. Twice weekly prophylaxis resulted in a reduction in bleeding frequency from 13 to nine bleeds per 100 days-about $30 \%$. To achieve this reduction 1657 units per bleed were needed compared with an average of 1018 units per bleed used by boys not on prophylaxis. In this group of boys, 13 bleeds which might be expected to occur while not on prophylaxis would need 13234 units of factor VIII, while the nine bleeds expected to occur while on prophylaxis would use 14913 units-an increase of about $12 \%$.

Thrice weekly prophylaxis resulted in a reduction of bleeding frequency from 16 to six bleeds per 100 days-atout $60 \%$; 4809 units per bleed were needed to achieve this reduction. In this group of boys 16 bleeds which might be expected to occur while not on prophylaxis would require 16288 units of factor VIII while the six bleeds expected to occur while on prophylaxis would use 28854 units-an increase of $77 \%$.

These results confirm the steeply escalating requirements for factor VIII when attempting to increase the efficacy of prophylaxis which we predicted in two controlled trials previously carried out at the Centre (Aronstam et al., 1976; 1977a). The increase in materials required is less than we predicted, but some of this is due to the increased amount of transfusion we now use in our own normal practice. Only $18 \%$ of Haemophilia Centre Directors in the UK used prophylaxis in 1975 (Aronstam et al., 1977b), while recent information (Jones et al., 1978) suggests an escalation in this form of treatment between 1976 and 1977. We believe that prophylaxis is likely to be responsible for an upsurge in the usage of factor VIII over the next few years.

An analysis of transfusion requirements at various sites shows that iliopsoas, retroperitoneal, and abdominal wall bleeds were the commonest bleeds which needed retransfusion within 24 hours, while bleeds into the extremities of the upper and lower limbs needed least retransfusions within 24 hours. Retroperitoneal bleeds needed most transfusions per episode, followed by iliopsoas, buttock, abdominal wall, and hip joint bleeds. It is striking that the transfusion requirements of bleeds below the diaphragm appear to diminish steadily the more peripheral they become, apart from calf bleeds which require more transfusions per bleed than those into the knee joint. This relationship does not hold for upper limb bleeds and may be related to weight bearing. We think it highlights the need for non-weight bearing during the acute phase of bleeds into the lower half of the body.

This work was supported by a grant from the Sir William Coxen Trust Fund.

\section{References}

Aronstam, A., Arblaster, P. G., Rainsford, S. G., Turk, P., Slattery, M., Alderson, M. R., Hall, D. E., and Kirk, P. J. (1976). Prophylaxis in haemophilia: A double-blind controlled trial. British Journal of Haematology, 33, 81-90.

Aronstam, A., Inwood, M. J., and Arblaster, P. G. (1977b). A comparison of current prophylactic therapy in Canada and the United Kingdom (Abstract). Thrombosis and Haemostasis, 38, 370.

Aronstam, A., Kirk, P. J., McHardy, J., Culver-James, J. W., McLellan, D. S., Turk, P., Rainsford, S. G., and Slattery, M. (1977a). Twice weekly prophylactic therapy in haemophilia A. Journal of Clinical Pathology, 30, 65-67.

Aronstam, A., Rainsford, S. G., and Painter, M. J. (1979). Patterns of bleeding in adolescents with severe haemophilia A. British Medical Journal, 1, 469-470.

Biggs, R., and Spooner, R. (1977a). Haemophilia treatment in the United Kingdom from 1969 to 1974. British Journal of Haematology, 35, 487-504.

Biggs, R., and Spooner, R. (1977b). Haemophilia Centre Directors' Annual Statistics for 1975 (Letter). British Journal of Haematology, 36, 447-449.

Denson, K. W. E. (1972). In Human Blood Coagulation, Haemostasis and Thrombosis, edited by R. Biggs, Appendix 2, p. 616. Blackwell Scientific Publications, Oxford.

Jones, P., Fearns, M., Forbes, C., and Stuart, J. (1978). Haemophilia A home therapy in the United Kingdom 1975-1976. British Medical Journal, 1, 1447-1450.

Requests for reprints to: $\operatorname{Dr}$ A. Aronstam, Treloar Haemophilia Centre, Lord Mayor Treloar Hospital, Alton, Hants, UK. 